\title{
Distributed Energy Resources Impact on Distribution System Reliability Under Load Transfer Restrictions
}

\author{
Armando M. Leite da Silva, Fellow, IEEE, Luiz C. Nascimento, Mauro Augusto da Rosa, Member, IEEE, \\ Diego Issicaba, Member, IEEE, and João A. Peças Lopes, Senior Member, IEEE
}

\begin{abstract}
Wind and solar power are well known intermittent power sources with high availability uncertainties. Hence, whenever they are integrated to distribution systems, these power sources can increase significantly the complexity of system operation. This paper presents an impact analysis of distributed energy resources integration on distribution systems, focusing mainly on reliability aspects. Therefore, an interesting algorithm to correctly determine the amount of capacity that may be transferred to other feeders is presented and discussed, taken into consideration the presence of distributed generation. The methodology is tested in a typical Brazilian distribution system, assuming the integration of a diesel-based combined heat and power unit, wind turbines, and solar panels. The results provide general insights regarding the benefits of applying distributed generation to alleviate load transfer restrictions.
\end{abstract}

Index Terms-Distributed energy resources, load transfer, Monte Carlo simulation, reliability assessment, solar power, wind power.

\section{INTRODUCTION}

A S SEVERAL large-scale systems, electrical power systems evolve based on trends motivated by economical, environmental, and societal drivers, as well as on the advances in lateral areas such as communication and information technologies. Such drivers have caused the advent of well-established initiatives around the world especially concerned with power systems such as: Modern Grid Initiative [1], IntelliGrid Initiative [2], European Smart Grids Technology Platform [3], and some smart grids policies and statements of policy [4], [5]. In general terms, these initiatives are characterized by the deployment of decentralized control and management solutions, the integration of renewable and distributed energy resources (DER), as well as the modernization of the power systems. From a more specific perspective, some directives can be recognized

Manuscript received December 22, 2011; revised February 16, 2012; accepted March 10, 2012. This work was supported by the National Council for Research and Development, CNPq, Ministry of Science and Technology, Brazil the CAPES Foundation, Ministry of Education, Brazil, and the Foundation for Science and Technology (FCT), Portugal. Paper no. TSG-00694-2011.

A. M. Leite da Silva is with UNIFEI, Federal University of Itajubá, Itajubá 37500-903, Brazil (e-mail: armando@unifei.edu.br)

L. C. Nascimento is with UFSJ, Federal University of São João del-Rei, Brazil (e-mail: nascimentolc@ufsj.edu.br).

M. Rosa, D. Issicaba, and J. A. Peças Lopes are with INESC Porto, Institute for Systems and Computer Engineering of Porto, Porto 4200-465, Portugal, and also with FEUP, Faculty of Engineering of the University of Porto, Porto 4200-465, Portugal (e-mail: marosa@inescporto.pt; dissicaba@inescporto.pt; jpl@fe.up.pt).

Color versions of one or more of the figures in this paper are available online at http://ieeexplore.ieee.org.

Digital Object Identifier 10.1109/TSG.2012.2190997 such as reliability, renewable resources, demand response, electric storage, and electric transportation [6].

DER comprises the distributed generation (DG), energy storage units, and loads under active demand-side management. Among these resources, distributed generation has experienced a significant increase during the past few years. Nevertheless, DG integration imposes several challenges to power distribution delivery. These challenges arise since the distribution systems infrastructure was designed assuming that the electric energy would be carried unidirectional from HV/MV substations downstream to customers. This assumption influences protection and control, and as a consequence, the distribution systems reliability. Hence, the complexity of operating the distribution systems as a whole increases with the integration of DG, and advanced control schemes [7] might be necessary to achieve an adequate and safe operation.

Despite these shortcomings, DG is deemed to enhance reliability, power quality, and to provide ancillary services [8]. Among the several benefits DG can provide to the distribution system operation, they can be used to alleviate the feeder loading to allow increase in load transfer capability. This increase depends considerably on the size, technology and the intermittency of the resource employed by the DG. Special attention has been given to wind and solar power due to environmental issues. However, these power sources along with their intermittencies can increase significantly the complexity of system analysis.

This paper presents an impact analysis of DER integration on distribution systems, focusing mainly on reliability aspects. The proposed methodology is based on a combination of analytical techniques (cut-sets) and chronological Monte Carlo simulation (MCS). It assesses the amount of capacity that may be transferred to other feeders, taking into consideration the presence of DG. The methodology is tested in a typical Brazilian distribution system assuming the integration of a diesel-based combined heat and power unit, wind turbines, and solar panels. The results are presented and discussed bearing in mind the reliability benefits of applying distributed energy resources to alleviate load transfer restrictions.

\section{DG COnNeCted to Distribution System}

There are a number of technical, environmental, regulatory, and commercial challenges for DER integration. It is widely recognized and reported in the literature that high penetration of DER in distribution networks can be both beneficial and unfavorable [9]. Both positive and negative impacts depend on various technical features, such as technology, size of the units, operation and control strategies used to deal with the DER, as well 
as their capacity and position in the network. Generally, DER studies as DG integration aim to search ways of managing the impact of DG penetration with respect to regulation, costs, location, size, as well as environmental and technical benefits.

In terms of problem evaluation, these are the major concerns to be considered. For instance, DG location can be highly influenced by the node of connection. Depending on where the generators are installed in the grid, the benefits and negative impacts may vary as well. The size of DG units can define the operation regime and the amount of energy delivered to the grid. DG also affects the voltage regulation and the limits of operation. DG capacity can indicate the current limits on lines and the power limit of the substation transformer. At this point, it is important to highlight that the gains in network capacity and possibility of investment deferral provided by DG connection can effectively contribute to operation conditions such as load transfer restrictions. The reduction of transfer restrictions is the main technical benefit evaluated in this paper.

DG impacts on the level of losses of the distribution network. It is largely used as the main function in such type of evaluation because it reflects in efficiency and, indirectly, impacts on capacity and voltage regulation. There is also regulation over losses defining penalization and rewards, what may be included in this type of evaluation. DG short-circuit level, which in fact has generally negative impact over operation of protection, depends on the DG technology used. Finally, DG ownership may impact on regulation, and can define whether the utility is allowed to own and conveniently install DG in the distribution network. In Europe, for instance, it is forbidden for the distribution network operators to own generating units mainly due the unbundling rules for electricity markets [10].

\section{Distribution System Reliability EVALUATION}

It is essential for electric utilities to track distribution system reliability levels and define performance indices to assess their basic function of providing a cost-effective and reliable power supply to all sectors of society. In the current competitive environment, all these utilities are under a tremendous pressure to reduce costs by all means. One of the immediate consequences is the deterioration of service quality. An interesting attempt to maintain an acceptable balance between service quality and costs is through a mechanism known as performance-based rates (PBR) [11], [12]. A PBR is a contract that rewards a utility for providing good reliability service and/or penalizes it for providing poor reliability levels.

In general, PBR is based on a procedure known by past performance or historical reliability assessment, and it is widely used by utilities. Future performance or predictive reliability assessment is another valuable reliability evaluation procedure, which can be used to determine system reinforcements and to compare expansion alternatives. Regardless of the procedure applied to measure the past or future performance of the supply adequacy at customer load points, the main indices used are: failure rate (usually interpreted as a frequency) $\lambda$, failure duration $r$, unavailability $U$, energy not supplied ENS, and for the system (or any group of customers or feeders) indices such as SAIFI, SAIDI, and CAIDI [13], [14]. These indices represent average values and, therefore, conventional distribution system reliability algorithms are generally able to assess these values.
These algorithms are based on Markov concepts in conjunction with minimal cut-set techniques (network modeling). They provide sufficiently accurate results for a wide range of practical distribution systems [14], even for large networks taking into account several practical aspects [15]. Due to the new competitive environment, other indices have emerged such as the interruption costs (e.g., ECOST = expected interruption cost, [16], [17], LOLC = loss of load cost [18], [19], etc.) and Maximum Continuous Interruption Duration per customer (MCID), which measures the amount of hours that a customer is continuously interrupted beyond an acceptable target value (MCIDT) [20]-[22]. Unfortunately, even average values associated with these indices cannot be computed by analytical methods [18], [19], [23]. Conversely, the sequential MCS is the natural tool to simulate chronological aspects. It is not only able to assess the usual reliability indices, but also their respective probability distributions [24]-[26]. Even maintenance schemes can be easily included in the simulation.

\section{A. Equipment, DER, and Load Modeling}

In chronological MCS, any equipment (e.g., lines, cables, disconnects, etc.) can be easily represented by the usual two-state Markovian model, defined by the associated failure and repair rates [14], [24]. Obviously, if necessary, non-Markovian models can be used in the simulation process. Different chronological load patterns per area or bus [19] can also be represented, as well as the fluctuation of generating capacities, a characteristic of renewable energy sources [27], [28]. In distribution systems reliability assessment [14], the supply is considered $100 \%$ reliable, i.e., always available with the necessary capacity. In this work, photovoltaic (PV) and wind power generation units will be considered $100 \%$ reliable, but their capacity will vary with time, using models similarly to those described in [27], [28]. Combined heat and power (CHP) units will also be considered 100\% reliable as the major substation supply. If needed, all sources can have their unavailabilities duly simulated by the chronological MCS algorithm.

\section{B. Chronological MCS for Distribution Systems}

The sequential MCS is able to reproduce the chronological evolution of the system by sampling stochastic sequences of system states [24]-[26]. These sequences are simulated based on the stochastic modeling of each system component and the chronological load model in the same time basis. The sequential MCS algorithm can estimate the system reliability indices considering the $N Y$ simulated years as given by (1):

$$
\widetilde{E}[G]=\frac{1}{N Y} \sum_{\mathrm{k}=1}^{N Y} G\left(y_{\mathrm{k}}\right) .
$$

Estimates of all the basic reliability indices can be represented by (1), depending on the definition of $G\left(y_{k}\right)$, where $y_{k}$ represents a sequence of system states in year $k$. For instance, the energy not supplied will be the summation of unsupplied energy associated with each interruption of a simulated year. The uncertainty around the estimated indices is given by the variance of the estimator, and the convergence of the simulation process is tested using the coefficient of variation $\beta$ [19], [24], [25]. 
The proposed algorithm is based on a combination of analytical techniques (minimal cut-sets) and chronological MCS [21]-[23]. It is described as follows:

i) Identify all minimal paths and cut-sets for all load points.

ii) Simulate the initial state of each component belonging to each minimal cut-set by nonsequential Monte Carlo simulation. Another unbiased possibility to this step is to chronologically connect all component simulated history; this procedure is used in this work.

iii) Generate different random numbers for both up and down times of each component belonging to each minimal cutset, and convert these numbers into times to failure and repair using the appropriate distributions.

iv) Identify the shortest time $\left(T_{M I N}\right)$ and set it as the clock of the process. The corresponding equipment is $E_{M}$.

v) Analyze the reliability performance for all load points, feeders or any specific group of customers and also for the system. This includes the search for possible switching actions, which are also simulated, based on some probability distributions or set as fixed values. The analysis should also consider time load variations of customers and other alternative sources.

vi) Based on the previous analysis, calculate contributions to reliability indices for all load points. EENS indices are properly calculated for those points with PV sources.

vii) Generate and add a new time (up or down) associated with equipment $E_{M}$. If the period of analysis (e.g., year) is not over yet, go back to step iv); otherwise, calculate reliability indices (load points and system) for the corresponding period and continue to step viii).

viii) Evaluate the coefficient of variation $\beta$ for a given reliability index (say, expected energy not supplied). If convergence is not achieved, return to step iv); otherwise, calculate the reliability measures (expected values and distributions) for all load points and system (or any group of customers), and stop the simulation process.

There is a number of aspects related with the MCS process that depends on some system operating assumptions. These involve, for instance, load transfer restrictions, load curtailment policy set at the substation level, floating capacity of some DER, etc. These are fully considered in the present work.

\section{Distribution System Decomposition}

Initially, it is necessary to identify the main feeders of the distribution system. An algorithm capable of automatically determining the system main feeders was developed. This algorithm consists of checking the connectivity between the branches and indicating the load points that use the same feeder to receive energy from the supply, without the need to close the Normally Open (N/O) points. Thus, the methodology consists of completely separating each of the feeders, and the N/O points that interconnect the feeders will be replaced by alternative energy supplies connected through N/O components [15], [22]. In terms of reliability, the disadvantage of using the proposed decomposition assumption is restricted to disregarding of some second order minimal cuts; only those which depend on switching involving N/O points. The contributions of these cuts to reliability indices are negligible most of the time. The full
TABLE I

LOAD LEVELS FOR DETERMINING N/O SWITCH CAPACITIES

\begin{tabular}{|l|c|c|c|}
\hline \multirow{2}{*}{} & \multicolumn{3}{|c|}{ Load Level } \\
\cline { 2 - 4 } & Low & Medium & High \\
\hline Load Factor $(\mathrm{pu})$ & 0.5 & 0.7 & 1.0 \\
\hline N/O Switch Factor $(\mathrm{pu})$ & 2 & 1.5 & 1.0 \\
\hline
\end{tabular}

procedure to account for the effects of transferring load through $\mathrm{N} / \mathrm{O}$ points in the load feeder will be described.

\section{IMPACT OF DG ON LOAD TRANSFER RESTRICTIONS}

The failure of one component of the electric system causes the opening of a protective device, with the objective of limiting the extension and severity of the fault. If there is a possibility of switching taking place, through the closing of N/O points, the interrupted loads outside the isolated area are transferred to another feeder. This transfer is dependent on technical restrictions, such as equipment overloading or voltage dropping problems. Neglecting these aspects would cause even greater problems in the loads being transferred and in the loads normally served by the feeder receiving the transfer.

In order to properly determine all technical limits, it is necessary to perform load flow analyses for all possible contingencies of the system, which may be computationally unfeasible in a chronological MCS process for real distribution networks. Nevertheless, of all the technical aspects to be taken into consideration, the one that may cause the greatest and most direct impact is the equipment capacity limit. The maximum capacity that may be transferred to one feeder is determined by:

- thermal capacity of conductors in the feeders, from the interconnection point to the supply source;

- installed capacity of the transformers and other equipment in the substation;

- capacity rating of these components under normal operating conditions.

By ignoring the maximum transfer capacity, an undesired protection operation may be initiated (e.g., interruption of loads outside the faulty area) and/or the damage of components, with even greater consequences. Thus, it is crucial to check the maximum load transfer capacity since this limit directly interferes with the reliability indices.

In order to illustrate how the load flow analysis can be replaced in a chronological reliability assessment of a distribution network, Table I presents three load levels: low, medium, and high. Each load level has an associated load and an N/O switch factors. As mentioned before, for a lower load level, there is a greater transfer factor in the N/O switch. The load factor is related to the nominal capacity of the load points and the $\mathrm{N} / \mathrm{O}$ switch factor is related to the worst capacity transfer condition, i.e., the capacity that may be transferred when there is the greatest load level (i.e., peak load). The parameters of Table I were chosen based on some data collected from Brazilian power utilities. Nevertheless, a power flow could be used to determine more reliable values for these parameters. Moreover, a greater number of load levels could be used. As this number increases, so does the number of cut-sets to be stored and the computational time, making impractical the analysis of very large-scale distribution systems. 
In a reliability evaluation that uses the state enumeration method (analytical), the load is to be considered constant. In this case, it is possible to identify exactly the load points that, due to the restriction of load transfer, stopped computing the switching time in order to compute the repair time of the faulty component. Therefore, it is possible to determine the load points influenced by the load restriction. For the chronological MCS, an algorithm that enables the use of load curves was developed. With it, for each time interval, the load is in different levels. Thus, in the load transfer process, one should check the load condition at the instant of failure occurrence to, then, compare it with the maximum transfer capacity. However, the checking of transfer restrictions at each instant of time may make it unfeasible the use of chronological MCS algorithms in real and large-scale distribution systems.

One way of carrying out a chronological MCS that addresses variable load curve and load transfer restriction between feeders is to determine minimal cut-sets for pre-determined load levels. The load curve variation is not only related to the capacity of the load points but also to the load transfer capacity between feeders. A lower load level will lead to a greater load transfer capacity. Only the cut-sets with N/O switching times are influenced by load transfer restriction. A cut-set may become a cut-set with repair time due to this restriction.

The proposed approach consists in determining the cut-sets with N/O switching time and with repair time for each of these three load levels: Low, Medium, and High. The steps for each level are described next:

a) Select a cut $C$ with N/O switching time and the load points $L P$ affected by this cut.

b) Check the capacity of the disconnecting N/O switch of the associated path of cut $C$. Compare the capacity found for the switch with the sum of the capacities of the load points that were affected by cut $C$.

c) If the capacity of the sum of the loads $L P$ is less than the capacity of the N/O switch, cut $C$ continues as first order cut with N/O switching time for these load points; go on to step $\mathrm{f}$ ).

d) If the capacity of the sum of the loads $L P$ is greater than the capacity of the N/O switch, one should find the next switch device of an N/O path, towards the feeding source and originating at the present $\mathrm{N} / \mathrm{O}$ device of cut $C$. The $\mathrm{N} / \mathrm{O}$ switch found will become the new maneuver device for load transfer.

e) Select the load points $L P$ in which at least one N/O path is not made up by the new switch device of cut $C$. The selected points will be the new $L P$. For the other load points, cut $C$ will shift from N/O switching time to repair time. Return to step c).

f) If there are more cuts with $\mathrm{N} / \mathrm{O}$ switching time, one should choose a new cut $\mathrm{C}$, the new load points LP affected by this cut, and return to step c). This test should be carried out with all cuts with N/O switching time.

During the chronological MCS, the capacity of each N/O switch will be changed according to the load level of the feeder that will receive the transfer, i.e., the capacity not used by the feeder may be transferred. This approximation is performed as to avoid the use of a load flow routine. Through the N/O switch capacity one can determine, by means of Table I, which load level the system is at and, consequently, which cut-set should be used in the simulation. For instance, if the load level is below 0.5 pu (per unit in relation to the peak), one should use a switch capacity factor of $2.0 \mathrm{pu}$ (per unit in relation to its nominal power rating). That means, more power can be transferred from the feeder with low load level condition. If the load level is between 0.5 and $0.7 \mathrm{pu}$, one should use a factor of $1.5 \mathrm{pu}$. Finally, if the load is between 0.7 and $1.0 \mathrm{pu}$, the switch capacity factor is 1.0 pu, i.e., one should use its standard power rating value.

The inclusion of renewable sources in the system also influences the transfer capacity of N/O switches. The transfer capacity floats according to the power generated by the renewable sources. If the renewable source is present in the feeder that failed, it will be checked if the path between the renewable source and the switch is disconnected. This makes it impossible the use of the source in the load transfer. If the renewable source is present in the feeder that will receive the transfer, it will always be taken into account, for only second order cuts, which were not taken into consideration in the decomposition simulation, would not allow the use of the source.

\section{ApPlichtion Results}

\section{A. System Characteristics}

The selected system to identify the contribution of DER on distribution system reliability under load transfer restrictions is a typical Brazilian distribution network (TBD), which occupies an area circa $550 \mathrm{~km}^{2}$ in a rural district [15]. This system is considered to be of a small size, for it has 148 branches and 61 load points distributed in four main feeders. The loads follow a chronological representation containing as many steps as there are hours in the year as in [29], with the exception of LP13, LP15, LP29, LP33, LP45, LP57, and LP60, which are set as constant values comprising an industrial behavior. The average repair or replacement time for most equipment is $2.4 \mathrm{~h}$, and the average switching time is set to $1 \mathrm{~h}$. Its geo-processed topology can be seen in [15].

Fig. 1 illustrates the feeders in a single line diagram, which was modified to include photovoltaic (PV), combined heat and power (CHP), and wind power generation units. These four feeders are connected by five different switches (SW-1, SW-2, SW-3, SW-4, and SW-5). The possibility of transferring load from Feeder 1 to 2 is assured by SW-1, (which has a double pathway to the load transfer) and also SW-4. The possibility of transferring load from Feeder 2 to 3 is assured by SW-5, and from Feeder 1 to 4 is assured by SW-3. The SW-2 consists of an internal possibility of transferring load of Feeder 1 . At the load points (LP) indicated in Fig. 1, six individual PV generation panels with capacity of $0.21 \mathrm{MW}$ were integrated [30]. In addition, two wind turbines of $2 \mathrm{MW}$ and a Diesel-based CHP unit of 1.1 MW were integrated as well [30]. Solar and wind generation powers bring with them different levels of output variations, which are properly represented by historical series of solar irradiation and wind speed converted to power [31], [32].

Regarding the operation conditions, after a fault is cleared and isolated, the feeders must be energized at least up to the point of common connections and the DG must start up and be synchronized in time to support load transferring. Notice that islanded operation is not allowed and loss of grid protection 


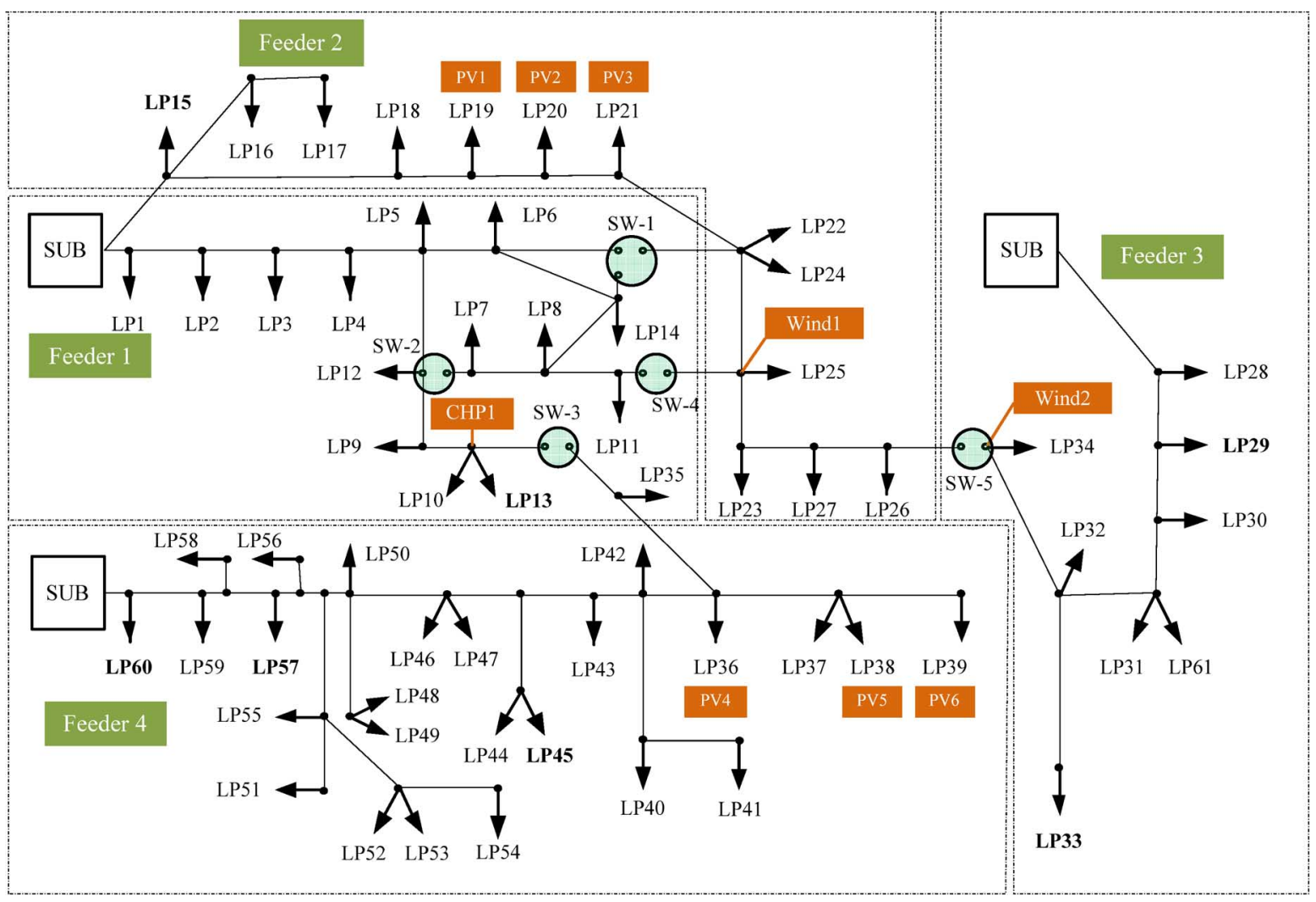

Fig. 1. Integration of PV, CHP, and wind generator units in the TBD system.

acts perfectly in disconnecting the DG after the occurrence of a fault. For the sake of the TBD system, it is emphasized that PV solar panels exhibit a nonlinear current/voltage characteristic producing maximum power at only one particular operating point, which varies with the solar irradiation [31] and panel temperature. Hence, grid-tie inverters with maximum power point tracking allow extracting the maximum power from the PV arrays and fast start-up times. Such times are small and can be neglected for load transfer analysis purposes.

In case of CHP units, start-up times can vary from some seconds to a few days according to their size and technology (steam turbine, reciprocating engine, gas turbine, micro turbine, fuel cell) [33]. For 1.1 MW diesel-based CHP generators and 2.0 MW wind generation units, total start-up and synchronization times range a few milliseconds [33], [34]. These times were also neglected in the load transferring evaluations. Finally, the TBD network shown in Fig. 1 is an illustrative example, so it does not represent the real operation of this system.

\section{B. Discussion of Results}

In order to identify the contribution of DER on distribution system reliability under load transfer restrictions, three different types of simulations are carried out:

- Without LR: it consists of a distribution system without load restrictions between feeders.

- With LR: it consists of a distribution system with load restrictions between feeders. In this case, the switch limit is considered, where the transfer capacity between feeders is limited to $400 \mathrm{~kW}$, with the exception of Switch 3 (SW-3) that is limited to $800 \mathrm{~kW}$ (from Feeder 4 to 1).

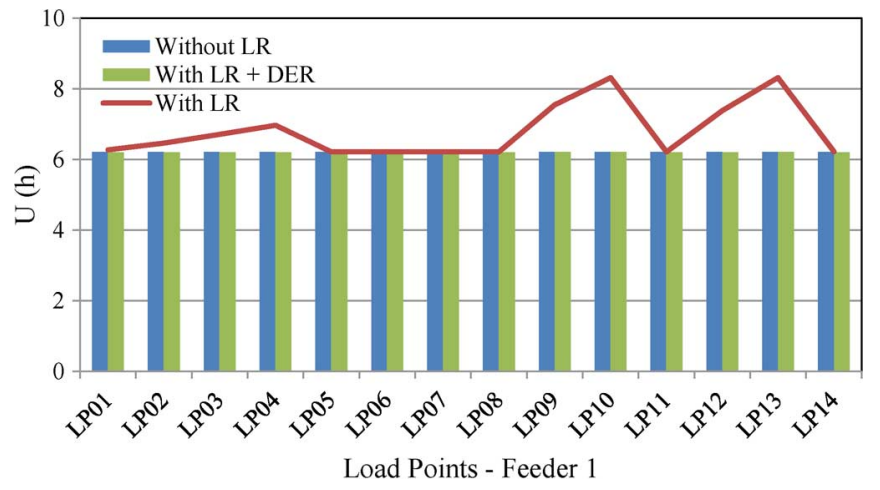

Fig. 2. Unavailability indices per load points-Feeder 1.

- With LR + DER: it consists of a distribution system with load restrictions between feeders in the same way as before. However, the presence of DER distributed along all feeders (Fig. 1) is considered.

Fig. 2 shows the unavailability indices for all load points in Feeder 1. Due to the presence of four switches, if a failure occurs, all loads can be transferred resulting in similar performances (Without LR). Observe that there is no impact of load restrictions on the following load points: LP05, LP06, LP07, LP08, LP11, and LP14. In fact, due to the possibility of transferring capacity between Feeders 1 and 2 through SW-1 and SW-4, these load points are suitably supported in case of failure events in Feeder 1. Due to its proximity to the substation, the LP01 is also supported right away in case of failure events. Conversely, points LP03, LP04, LP09, LP10, LP12, and LP13 are the most affected by the load restrictions of Feeder 2. 


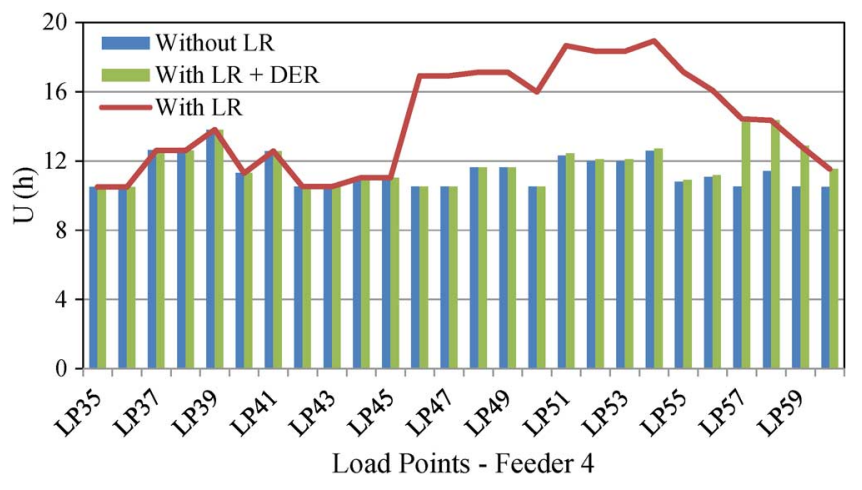

Fig. 3. Unavailability indices per load points-Feeder 4.

As expected, it is not possible to transfer the whole set of load from Feeder 1 to 2 . In general, these set of load points should wait, on average, for $2.4 \mathrm{~h}$ of repair time, instead of an average switching time, which is set to $1 \mathrm{~h}$. Hence, the results presented in the simulation "With LR" for these load points appear with high values of unavailability index (in red), when compared to the simulation results "Without LR" (in blue). Another possibility would be to transfer the load capacity from Feeder 1 to 4 , which in fact is restricted by the proximity of the industrial load, located at LP13, from SW-3. This industrial load is represented by a constant load value of $880 \mathrm{~kW}$. Regardless of this fact, the switch capacity of SW-3 is $400 \mathrm{~kW}$, which also could unable the transfer of the complete set of load points from one feeder to another.

The integration of DER into the distribution system may directly modify the transferring capacities involved in this analysis. Notice that the connections of CHP1 and PV4, PV5, and PV6 enable a certain level of transferring capacity through SW-3. Moreover, the integration of Wind1 and PV1, PV2, and PV3 allows transferring capacity through SW-1 and SW-4. This new condition brings the real benefit from DER, where the transferring capacities results in the simulation "With LR+DER" (in green) may be compared with those "Without LR (in blue)" ones. Nevertheless, it is important to mention that the PV integration has a marginal benefit over the unavailability index of the load points of Feeder 1.

Another set of evaluations is shown in Fig. 3, where the unavailability index of the load points of Feeder 4 is assessed. As the switch capacity transfer of SW-3 is $800 \mathrm{~kW}$, the range of load points from LP35 to LP45 may be transferred from Feeder 4 to 1 . This may be observed in Fig. 3, when one compares the simulation results "Without LR" (in blue) to "With LR" (in red). Meanwhile, as LP45 consists of an industrial load of $600 \mathrm{~kW}$, there is a large consumption of this transferring procedure direct to this LP45, which reduces the benefit over the rest of the load points. Once again, DER benefits are strongly evident where CHP1 has increased the transferring capacity through the SW-3. This makes it possible to accept part of this load that comes from the range of load points from LP46 to LP54. Conversely, the range of load points LP55 to LP60 receives little benefit from the CHP1 integration.

Considering a $\beta=1 \%$, each case takes, on average, $15 \mathrm{~s}$ to be run in an Intel Core 2 Duo, $2 \mathrm{GHz}$ processor.

In Fig. 4, it is shown the EENS index and its implications over Feeder 2. It can be seen that the EENS index behaves without

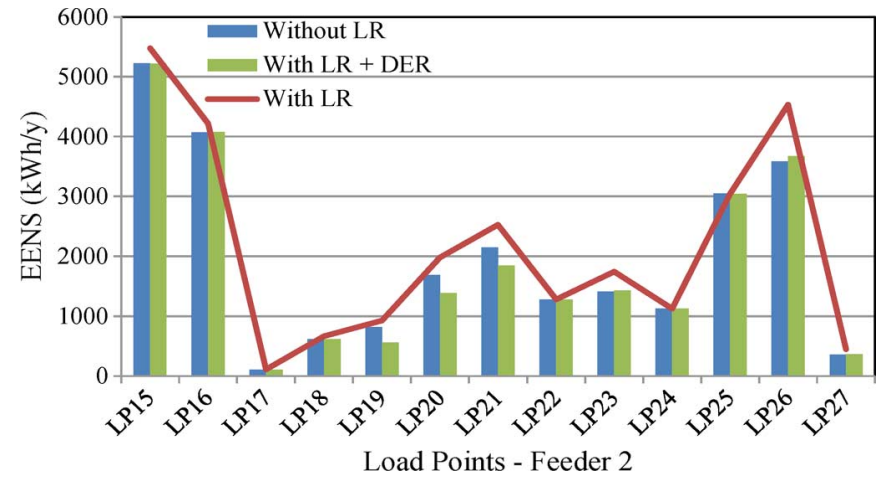

Fig. 4. EENS indices per load points-Feeder 2.

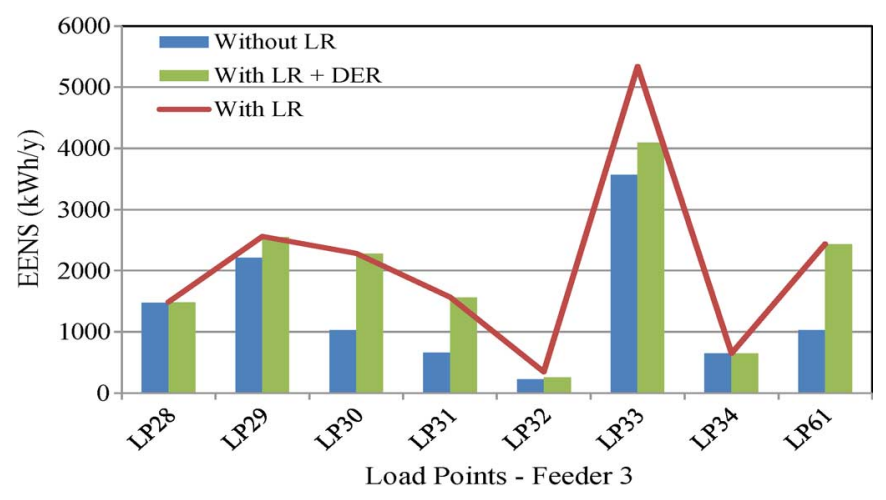

Fig. 5. EENS indices per load points-Feeder 3.

influence of the load transfer restrictions, mainly in the simulation results "Without LR" and "With LR" at load points LP22, LP24, and LP25. It means that the power transferring through SW-1 and SW-4 is only sufficient to supply these load points during a load transfer. In this case, SW-5 is unable to transfer load to Feeder 3, mainly because of the two industrial loads connected to this feeder. On the other hand, it is evident that the integration of Wind1, Wind2, PV1, PV2, and PV3 improves the performance of the whole set of load points in this feeder, mitigating the EENS index.

Some interesting results appear with the DER integration on some specific load points, where the EENS index "With LR+DER" may present results even better than "Without LR." The LP19, LP20, and LP21 are some examples of this condition. The simulation results "With LR+DER" present EENS index inferior to the "Without LR" ones. It can be explained due to the use of PV, which can supply consumers even in cases where the utility is unable to supply them. A simple analysis of the EENS index over Feeder 3 shows that the results revealed the same behavior as in Feeder 2, as presented in Fig. 5. LP28 and LP34 are not affected by load restrictions during the load transfer procedure, mainly due to the proximity to the substation and to SW-5. In fact, the integration of Wind 2 improves the EENS index on LP32 and LP 33, which is not extended to the other set of load points because LP33 consists of an industrial load of $873 \mathrm{~kW}$, requiring most part of the capacity transferred.

Tables II and III show the penalties (unavailability, frequency, and $M C I D$ indices) calculated for all load points of the four feeders of the TBD system. Limit standards of $20 \mathrm{~h} / \mathrm{yr}, 20 \mathrm{f} / \mathrm{yr}$, and $M C I D_{T}=3 \mathrm{~h}$ were considered for these three reliability indices, respectively. An average tariff of $0.20 \mathrm{US} \$ / \mathrm{kWh}$ was also considered for assessing the penalties [20]. Obviously, the 
This article has been accepted for inclusion in a future issue of this journal. Content is final as presented, with the exception of pagination.

TABLE II

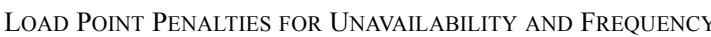

\begin{tabular}{|c|c|c|c|c|c|}
\hline \multicolumn{2}{|r|}{ Feeder } & 1 & 2 & 3 & 4 \\
\hline \multirow{3}{*}{ 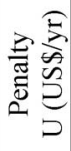 } & Without LR & 2.48 & 727.9 & 123.7 & 631.2 \\
\hline & With LR & 167.91 & 1608.7 & 1822.9 & 7142.8 \\
\hline & With LR + DER & 3.47 & 743.8 & 1547.5 & 1753.1 \\
\hline \multicolumn{2}{|c|}{ Penalty Freq. (US\$) } & 2.84 & 1397.1 & 642.6 & 1231.9 \\
\hline
\end{tabular}

TABLE III

LOAD POINT PENALTIES FOR MCID

\begin{tabular}{|c|c|c|c|c|c|}
\hline \multicolumn{2}{|r|}{ Feeder } & 1 & 2 & 3 & 4 \\
\hline \multirow{3}{*}{ 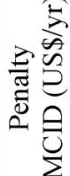 } & Without LR & 549.9 & 2374.4 & 1379.3 & 2355.0 \\
\hline & With LR & 2453.7 & 4868.2 & 8053.0 & 11717.4 \\
\hline & With LR + DER & 548.0 & 2476.3 & 6552.5 & 4608.8 \\
\hline
\end{tabular}

TABLE IV

EXPECTED ENERGY NOT SUPPLIED

\begin{tabular}{|c|l|c|c|c|c|}
\hline \multicolumn{2}{|c|}{ Feeder } & 1 & 2 & 3 & 4 \\
\hline \multirow{2}{*}{\begin{tabular}{l}
$y$ \\
\cline { 1 - 5 }
\end{tabular}} & Without LR & 11613 & 26015 & 19818 & 22175 \\
\cline { 2 - 6 } & With LR & 13474 & 28527 & 25321 & 29474 \\
\cline { 2 - 6 } & With LR + DER & 11601 & 25248 & 23894 & 23667 \\
\hline
\end{tabular}

failure frequency does not depend on the load restrictions. For all other indices, the results for the three load restriction cases (i.e., "Without LR," "With LR," and "With LR + DER") are shown.

For instance, the penalties due to the $U$ indices in Feeder 4 is reduced from 7142.8 to $1753.1 \mathrm{US} \$ / \mathrm{yr}$, when DER is included. Note that this penalty could not be lower than $631.2 \mathrm{US} \$ / \mathrm{yr}$, which is the value obtained under no load transfer restrictions. It can be observed that the penalties in all feeders are dramatically reduced. Some of them (e.g., Feeders 1 and 2) are diminished up to almost the same level as it would be with no load transfer restrictions. These remarks can also be made for the MCID penalties, as shown in Table III. These penalties are the highest in the system. In Feeder 4, the MCID penalty reached $11717.4 \mathrm{US} \$ / \mathrm{yr}$ with load restrictions and this value is reduced to $4608.8 \mathrm{US} \$ / \mathrm{yr}$ when DER are included. There is no doubt about the benefits of the proposed DG in the TBD network.

In relation to the EENS indices (Table IV), the presence of DG in the system is also significant. As it could be expected, in some feeders the EENS indices considering DG (i.e., "With LR + DER") are smaller than the base case (i.e., "Without LR"). This conclusion can be extended to the LOLC indices shown in Table V. These costs were calculated using the same unit interruption cost values described in [18]. Three categories were used: industrial, commercial, and residential.

The total LOLC are: a) 149897 US\$/yr in case "Without LR"; b) $175868 \mathrm{US} \$ / \mathrm{yr}$ in case "With LR"; and c) $154517 \mathrm{US} \$ / \mathrm{yr}$ in case "With LR + DER." By including DG, there will be a reduction of 21351 US\$/year or the loss of load costs.

Table VI shows the traditional SAIDI (under the three conditions) and SAIFI indices for the four feeders in the system.
TABLE V

LOSS OF LOAD COST

\begin{tabular}{|c|c|c|c|c|c|}
\hline \multicolumn{2}{|r|}{ Feeder } & 1 & 2 & 3 & 4 \\
\hline \multirow{3}{*}{ 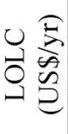 } & Without LR & 20099 & 56296 & 34211 & 39291 \\
\hline & With LR & 22864 & 60350 & 42440 & 50214 \\
\hline & With LR + DER & 20065 & 53117 & 40309 & 41026 \\
\hline
\end{tabular}

TABLE VI

SAIDI AND SAIFI INDICES

\begin{tabular}{|c|c|c|c|c|c|}
\hline \multicolumn{2}{|r|}{ Feeder } & 1 & 2 & 3 & 4 \\
\hline \multirow{3}{*}{ 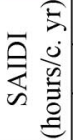 } & Without LR & 6.21 & 10.80 & 6.19 & 10.87 \\
\hline & With LR & 6.94 & 11.65 & 9.30 & 13.66 \\
\hline & With LR + DER & 6.21 & 10.84 & 8.68 & 11.80 \\
\hline \multicolumn{2}{|c|}{ SAIFI (int./cust. yr) } & 8.78 & 14.75 & 8.48 & 14.87 \\
\hline
\end{tabular}

By including DG in the TBD network, the SAIDI indices for Feeders 1 and 2 become almost the same as there were no restrictions under load transfer conditions. But the benefits in Feeders 3 and 4 are very significant: from 9.30 to $8.68 \mathrm{~h} /$ customer yr and from 13.66 to $11.80 \mathrm{~h} /$ customer yr. In relation to SAIFI index, there is obviously no improvement, as it could be expected.

\section{CONCLUSIONS}

This work described a new methodology based on minimal cut-sets and chronological Monte Carlo simulation (MCS) to assess the impact on the reliability indices, when distributed energy recourses (DER) are integrated into distribution systems. Load transfer restrictions and distributed generation (DG) were emphasized in this work. The proposed approach proved to be very accurate and also efficient from the computational point of view. From the reliability point of view, it becomes evident the benefits of integrating DG into distribution networks. Besides the increase on the amount of energy available in the grid, its distribution efficiency is enhanced. In the future, microgrids, energy storage units, and loads under active demand-side management will also be considered by the proposed reliability assessment tool. Obviously, other studies (e.g., investment costs, transmission losses, power quality, voltage stability, etc.) have to be carried out to conclude about the integration benefits of DER into distribution networks.

\section{REFERENCES}

[1] National Energy Technology Laboratory, A System View of the Modern Grid (Appendix A1: Self-Heals), U.S. Department of Energy, Tech. Rep., Jan. 2007.

[2] Electric Power Research Institute, The Intelligrid Consortium Research and Development Plan 2005-2007, Tech. Rep., Feb. 2005.

[3] Advisory Council for the Technology Platform for Europe's Electricity Networks of the Future, European Technology Platform Smartgrids: Strategic Deployment Document for Europe's Electricity Networks of the Future European Commission, Tech. Rep., Sep. 2008.

[4] Smart Grid Policy U.S. Federal Energy Regulatory Commission (FERC), Docket PL09-4-000, 2009.

[5] Title XIII-Smart Grid, Sec. 1301, Statement of Policy on Modernization of Electricity Grid Energy Independence and Security Act of 2007.

[6] K. Moslehi and R. Kumar, "A reliability perspective of the smart grid," IEEE Trans. Smart Grid, vol. 1, no. 1, pp. 57-64, Jun. 2010. 
[7] D. Issicaba, N. J. Gil, and J. A. Peças Lopes, "Islanding operation of active distribution grids using an agent-based architecture," in Proc. IEEE PES Conf. Innov. Smart Grid Technol. (ISGT Europe), Gothenburg, Sweden, Oct. 2010.

[8] D. Issicaba, J. A. Peças Lopes, and M. A. Rosa, "Distribution systems performance evaluation considering islanded operation," in Proc. Power Syst. Comput. Conf. (PSCC), Stockholm, Sweden, Aug. 2011.

[9] L. F. Ochoa, A. Padilha-Feltrin, and G. Harrison, "Evaluating distributed generation impacts with a multiobjective index," IEEE Trans. Power Del., vol. 21, no. 3, pp. 1452-1458, 2006.

[10] G. P. Harrison, A. Piccolo, P. Siano, and A. R. Wallace, "Exploring the tradeoffs between incentives for distributed generation developers and DNOs," IEEE Trans. Power Syst., vol. 22, no. 2, pp. 821-828, 2007.

[11] R. E. Brown and J. J. Burke, "Managing the risk of performance based rates," IEEE Trans. Power Syst., vol. 15, no. 2, pp. 893-898, May 2000.

[12] R. Billinton, L. Cui, and Z. Pan, "Quantitative reliability considerations in the determination of performance-based rates and customer service disruption payments," IEE Proc. Gener. Transm. Distrib., vol. 149, no. 6, pp. 640-644, Nov. 2002.

[13] IEEE Guide for Electric Power Distribution Reliability Indices, IEEE Std. 1366-2003, IEEE PES Transmission and Distribution Committee, May 2004.

[14] R. Billinton and R. N. Allan, Reliability Evaluation of Power Systems, 2nd ed. New York: Plenum, 1996.

[15] A. M. Leite da Silva, A. M. Cassula, and C. E. Sacramento, "Reliability evaluation of distribution systems under load transfer restrictions," in Proc. 7th Int. Conf. PMAPS - Probab. Methods Appl. Power Syst., Naples, Italy, Sep. 9-14, 2002.

[16] R. Billinton and P. Wang, "Distribution system reliability cost/worth analysis using analytical and sequential simulation techniques," IEEE Trans. Power Syst., vol. 13, no. 4, pp. 1245-1250, Nov. 1998.

[17] P. Wang and R. Billinton, "Reliability cost/worth assessment of distribution systems incorporating time-varying weather conditions and restorations resources," IEEE Trans. Power Del., vol. 17, no. 1, pp. 260-265, Jan. 2002.

[18] L. A. F. Manso, A. M. Leite da Silva, and J. C. O. Mello, "Comparison of alternative methods for evaluating loss of load costs generation and transmission systems," Electr. Power Syst. Res., vol. 50, no. 2, pp. 107-114, May 1999.

[19] A. M. Leite da Silva, L. A. F. Manso, J. C. O. Mello, and R. Billinton, "Pseudo-chronological simulation for composite reliability analysis with time varying loads," IEEE Trans. Power Syst., vol. 15, no. 1, pp. 73-80, Feb. 2000.

[20] Resolution no. 24, ANEEL-Brazilian Electricity Regulatory Agency [Online]. Available: http://www.aneel.gov.br, Jan. 2000

[21] A. M. Leite da Silva, W. F. Schmitt, A. M. Cassula, and C. E. Sacramento, "Analytical and Monte Carlo approaches to evaluate probability distributions of interruption duration," IEEE Trans. Power Syst., vol. 20, no. 3, pp. 1341-1348, Aug. 2005.

[22] A. M. Leite da Silva, A. M. Cassula, L. C. Nascimento, J. C. Freire, Jr., C. E. Sacramento, and A. C. R. Guimarães, "Chronological Monte Carlo-based assessment of distribution system reliability," in Proc. 9th PMAPS-Probab. Methods Appl. Power Syst., Stockholm, Sweden, Jun. 11-15, 2006.

[23] R. N. Allan and M. G. da Silva, "Evaluation of reliability indices and outage costs in distribution systems," Trans. Power Syst., vol. 10, no. 1, pp. 413-419, Feb. 1995.

[24] R. Billinton and W. Li, Reliability Assessment of Electric Power Systems Using Monte Carlo Methods. New York: Plenum, 1994.

[25] R. Y. Rubinstein and D. P. Kroese, Simulation and the Monte Carlo Methods (2nd Edition.). New York: Wiley, 2007.

[26] A. M. Leite da Silva and R. A. González-Fernández, "Reliability assessment of time-dependent systems via sequential cross-entropy Monte Carlo simulation," IEEE Trans. Power Syst., vol. 26, no. 4, pp. 2381-2389, Nov. 2011.

[27] J. A. Peças Lopes, M. Matos, A. M. Leite da Silva, and W. S. Sales et al., "Dealing with intermittent generation in the long-term evaluation of system adequacy and operational reserve requirements in the Iberian peninsula," presented at the Cigré Proc., Paris, France, Aug. 2008, Paper C1-304.

[28] A. M. Leite da Silva, W. S. Sales, L. A. F. Manso, and R. Billinton, "Long-term probabilistic evaluation of operating reserve requirements with renewable sources," IEEE Trans. Power Syst., vol. 25, no. 1, pp. 106-116, Feb. 2010.
[29] IEEE Reliability Test System Task Force of the Application of Probability Methods Subcommittee, "IEEE reliability test system," IEEE Trans. Power App. Syst., vol. 1, pp. 2047-2054, 1979.

[30] J. A. Peças Lopes, C. L. Moreira, and A. G. Madureira, "Defining control strategies for MicroGrids islanded operation," IEEE Trans. Power Syst., vol. 21, no. 2, pp. 916-924, May 2006.

[31] Photovoltaic Geographical Information System (PVGIS) Geographical Assessment of Solar Resource and Performance of Photovoltaic Technology [Online]. Available: http://re.jrc.ec.europa.eu/pvgis/index.htm

[32] NREL - National Renewable Energy Laboratory, Wind Power Data [Online]. Available: http://www.nrel.gov

[33] U. S. Environmental Protection Agency (EPA), Catalog of CHP Technologies, Tech. Rep., Dec. 2008.

[34] F. Olsina and C. Larisson, "Optimization of spinning reserve in stand-alone wind-diesel power systems," in Wind Power. Rijeka, Croatia: InTech, 2010, ch. 19 [Online]. Available: http://www.intechopen.com/books/wind-power/optimization-of-spinning-reserve-in-stand-alone-wind-diesel-power-systems

Armando M. Leite da Silva (S'77-M'78-SM'91-F'00) was born in Rio de Janeiro, Brazil, in 1954. He received the B.Sc. degree from the Catholic University of Rio de Janeiro (PUC-Rio) in 1975, the M.Sc. degree from the Federal University of Rio de Janeiro (COPPE-UFRJ) in 1977, and the Ph.D. degree from University of Manchester (UMIST), U.K., in 1980.

He worked at the Electrical Engineering (EE) Department, PUC-Rio, as a Professor until 1994. From 1990 to 1991, he was Visiting Researcher at the Research Division of Ontario Hydro, Canada. From 2003 to 2004, he was a Visiting Researcher at the Power System Unit, INESC Porto, Portugal. Since 1994, he has been a Professor at the Institute of Electric Systems and Energy, Federal University of Itajubá (UNIFEI), Brazil.

Prof. Leite da Silva received the Sebastian Z. de Ferranti Premium Award from the Power Division of the IEE, U.K., in 1992. In 2010, he was recognized with the PMAPS Merit Award for his contributions to probabilistic methods. In 2011, he received the IEEE PES Technical Committee (PSACE) Prize Paper Award.

Luiz Carlos do Nascimento was born in São Paulo, Brazil, in 1980. He received the B.Sc. and M.Sc. degrees in EE from the State University of São Paulo (UNESP) in 2003 and 2005, respectively, and the Ph.D. degree in EE from UNIFEI in 2009.

Since 2010, he has been an Associate Professor at the Electrical Engineering Department, Federal University of São João del-Rei (UFSJ), Brazil. His research interests include reliability assessment and optimization.

Mauro Augusto da Rosa received the B.Sc. and M.Sc. degrees in EE from the Catholic University of Rio Grande do Sul (PUCRS), Porto Alegre, Brazil, in 1998 and 2003, and his Ph.D. degree in EE from Faculty of Engineering, University of Porto (FEUP), Portugal, in 2009.

$\mathrm{He}$ is a researcher and develops his activities in the Power Systems Unit at INESC Porto, Portugal. His research interests include distributed artificial intelligent, intelligent agents, and power system reliability.

Diego Issicaba (M'07) received the B.S. and M.S. degrees in EE from the Federal University of Santa Catarina, Brazil, in 2006 and 2008, respectively. He is currently pursuing a Ph.D. degree from the MIT Portugal Program on Sustainable Energy Systems, FEUP, Porto, Portugal.

$\mathrm{He}$ is also associated with INESC Porto. His research interests include smart grid operation and control and multi-agent technology.

João A. Peças Lopes (M'80-SM'94) received the B.S. and Ph.D. degrees in electrical engineering from the University of Porto, Porto, Portugal, in 1981 and 1988, respectively.

Since 2008, he is a full Professor of the Department of Electrical and Computer Engineering, Faculty of Engineering, University of Porto. He is currently the Director of the Ph.D. Program on Sustainable Energy Systems of the Faculty of Engineering, University of Porto. He is also a Director of the Institute for Systems and Computer Engineering of Porto (INESC Porto). He is responsible by INESC Porto activities in several EU financed research projects. His research interests include microgrids, smart grid operation, and control. 